\title{
Retinal vein occlusion: A form of venous thrombosis or a complication of atherosclerosis?
}

\section{A meta-analysis of thrombophilic factors}

\author{
Mirian C. H. Janssen', Martin den Heijer², Johannes R. M. Cruysberg'3, Hub Wollersheim I, 4, Sebastian J. H. Bredie' \\ 'Department of General Internal Medicine, ${ }^{2}$ Department of Endocrinology and Epidemiology and Biostatistics, ${ }^{3}$ Department of Ophtalmology \\ and ${ }^{4}$ Centre for Quality of Care Research, Radboud University Medical Centre, Nijmegen, The Netherlands
}

\section{Summary}

Previous studies have shown an increased risk of retinal vein occlusion (RVO) in patients with hypertension, hypercholesterolemia and diabetes mellitus. Literature on the association between thrombophilic factors and RVO consists of small studies and case reports. The objective was to determine the relationship between thrombophilic risk factors and RVO. Thrombophilic risk factors analyzed were hyperhomocysteinemia, MTHFR gene mutation, factor $V$ Leiden mutation, protein $\mathrm{C}$ and $\mathrm{S}$ deficiency, antithrombin deficiency, prothrombin gene mutation, anticardiolipin antibodies and lupus anticoagulant. For all currently known thrombophilic risk factors odds ratios for RVO were calculated as estimates of relative risk. The odds ratios were $8.9(95 \% \mathrm{Cl} 5.7-13.7)$ for hyperhomocysteinemia, 3.9 $(95 \% \mathrm{Cl} 2.3-6.7)$ for anticardiolipin antibodies, I.2 (95\% Cl 0.9 -I.6) for MTHFR, I.5 (95\% Cl I.0 - 2.2) for factorV Leiden mutation and I.6 ( $95 \% \mathrm{Cl} 0.8-3.2)$ for prothrombin gene mutation. In conclusion, regarding thrombophilic risk factors and RVO there is only evidence for an association with hyperhomocysteinemia and anticardiolipin antibodies, factors that are known as risk factors for venous thrombosis as well as for arterial vascular disease. The minor effect of factor $V$ Leiden mutation and the protrombin gene mutation (risk factors for venous thrombosis only) suggests that atherosclerosis might be an important factor in the development of CRVO.

\section{Keywords}

Retinal vein thrombosis, retinal vein occlusion, risk factors, hyperhomocysteinemia, anticardiolipin antibodies

Thromb Haemost 2005; 93: 1021-6

\section{Introduction}

Retinal vein occlusion (RVO) is the second most common retinal vascular occlusive disease after diabetic retinopathy affecting not only elderly, but also young patients. A previous large population-based study reported a 4-year incidence of retinal vein occlusion of 2.14 cases per 1000 of general population older than 40 years and 5.36 cases per 1000 of general population older than 64 years (1). Retinal vein occlusions may affect the venous blood supply of the entire retina (central RVO), half of the retina (hemicentral RVO) or a quadrant drained by one of the branches of the central retinal vein (branch RVO). Retinal vein thrombosis causes increased venous pressure and may lead to retinal capillary decompensation with macular edema and subsequent visual loss. The exact pathogenesis of RVO is unclear. Of virchow's three classical factors that play a role in thrombogenesis- stasis, vessel damage and hypercoagulability- two have been frequently reported in patients with RVO. Open-angle glaucoma is the most frequent local alteration predisposing to RVO as it compromises venous outflow by increased intra-ocular pressure (2-5). Degenerative changes of the vessel wall, abnormal perivascular changes, and abnormal haematologic factors constitute as the primary mechanisms of vessel occlusion. Over the last few years, hypercoagulability, another Virchow factor, has attracted a considerable amount of interest for the internal medicine physician.

Previously, large studies using hospital-based controls have shown an increased risk of RVO in patients with hypertension, diabetes mellitus, atherosclerosis and hypercholesterolemia (6-14). Literature on associated thrombophilic abnormalities in various types of RVO has accumulated over the years, predominantly based on retrospective retrieval of information from case records of variable numbers of patients seen in routine clinical practice (15). Prospective studies on this subject however are 


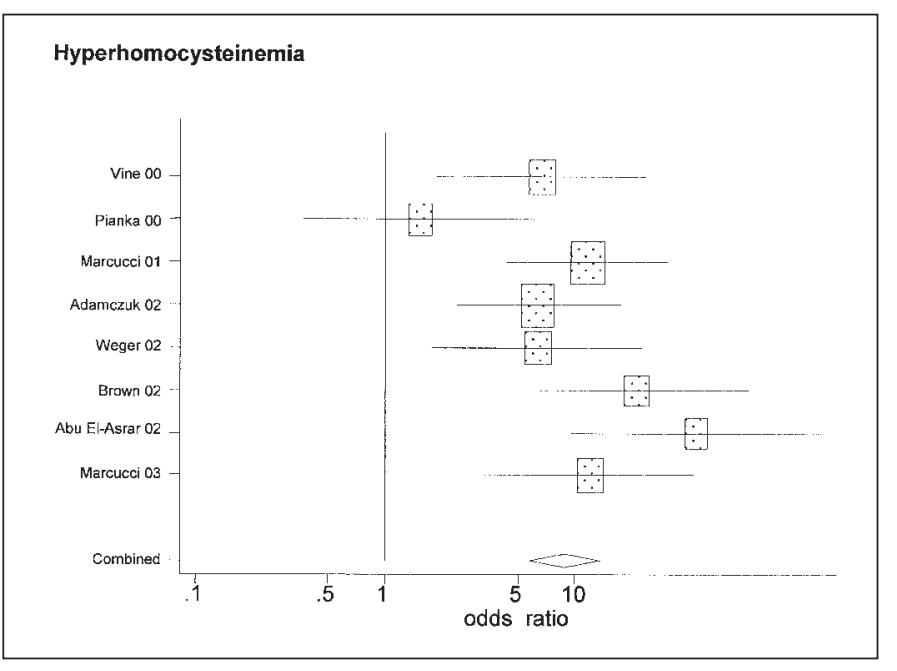

Figure I: Overall odds ratios and $95 \%$ confidence intervals for RVO with hyperhomocysteinemia. The combined odds ratio for the sub-totals for each study design and their $95 \% \mathrm{Cl}$ are indicated by the diamond. The size of the diamond is inversely proportional to the variance of the log odds ratio and the width of the diamond represents the $95 \% \mathrm{Cl}$.

rare. The following is a meta-analysis of the literature on the relationship between currently known thrombophilic risk factors and retinal venous occlusive disease, including the genetic alterations of haemostasis.

\section{Methods}

\section{Selection of studies}

Eligible studies were identified by searching the electronic literature (Medline) for relevant reports published between 1966 to 2004 using the terms 'retinal occlusion', 'retinal vein thrombosis' combined with 'risk factors', 'thrombophilia' or 'coagu-

\section{MTHFR}

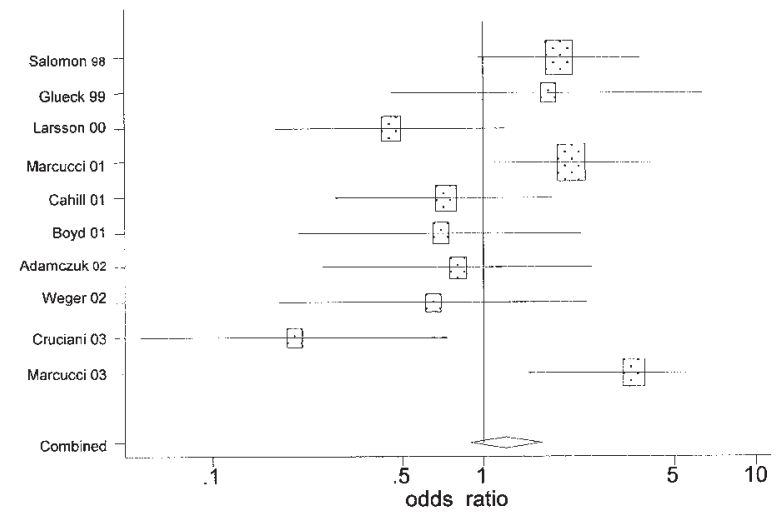

Figure 2: Overall odds ratios and $\mathbf{9 5 \%}$ confidence intervals for RVO with MTHFR. The combined odds ratio for the sub-totals for each study design and their $95 \% \mathrm{Cl}$ are indicated by the diamond. The size of the diamond is inversely proportional to the variance of the log odds ratio and the width of the diamond represents the $95 \% \mathrm{Cl}$. lation abnormalities'. We also manually searched reference lists of relevant studies identified.

Relevant titles and abstracts were reviewed in a single reviewer format. Articles were retrieved if they were case-control studies, retrospective or prospective, in which the controls were healthy adults with no history of thrombosis. To avoid acknowledged and covert duplication of data, only the most recent and complete series reported by investigators were included in the analysis. Studies were assessed independently by two of the authors (Mirian Janssen and Martin den Heijer).

\section{Statistical analysis}

For all analyses, summary estimates were obtained by taking an inverse-variance weighted average of the log odds ratios from individual studies. Heterogeneity was assessed using standard Chi-squared tests $(16,17)$.

\section{Results}

In total, 138 reports, including case-reports on the role of coagulation abnormalities in retinal venous occlusive disease were identified in the literature. Of these, 26 were case control studies that were used for further analysis. No prospective or intervention studies were found. In most of the studies ophthalmic patients without retinal vascular occlusive disease were used as controls, whereas in other studies healthy adults and blood donors with no history of thrombosis were used.

\section{Hyperhomocysteinemia and methylenetetrahydro- folate reductase $\mathbf{C 6 7 7 T}$}

Eleven case control studies on the role of elevated plasma homocysteine were found (18-28) with a total of 527 patients with any type of retinal vein occlusion and 955 control subjects. In all studies fasting homocysteine above the $95^{\text {th }}$ percentile of controls was defined as fasting hyperhomocysteinemia . Odds ratio's varied between 1.5 and 43.5 (Fig. 1).

The overall odds ratio for homocysteine $>95^{\text {th }}$ percentile was $8.9(95 \%$ CI 5.7 to 13.7$)$ with no significant heterogeneity $(\mathrm{p}=0.073)$.

In total, 10 case-control studies on the role of MTHFR were found $(19,23,28-35)$ with a total of 581 patients with retinal vein occlusion and 1080 control subjects. Results demonstrated odds ratio's of 0.5 to 3.5. The overall odds ratio for MTHFR as risk factor for RVO was 1.2 (95\% CI 0.9 to 1.6) with significant heterogeneity ( $p=0.003)$ (Fig. 2).

\section{Factor V Leiden mutation}

Fourteen case-control studies on the role of FV Leiden mutation were found $(19,22,23,28,31,32,34,36-42)$ with a total of 792 patients with any type of retinal vein occlusion and 1418 control subjects. The odds ratio's were between 0.6 and 6.9. Figure 3 demonstrates that some authors failed to find a high prevalence of FV Leiden in RVO patients with respect to controls whereas others demonstrated a significant association. The overall adjusted odds ratio for FV Leiden for the risk of RVO was 1,5 (95\% CI 1.0 to 2.2$)$, with no heterogeneity $(\mathrm{p}=0.135)$. Two studies in which none of the controls had the mutation could not be included in the calculation. 


\section{Factor V mutation}

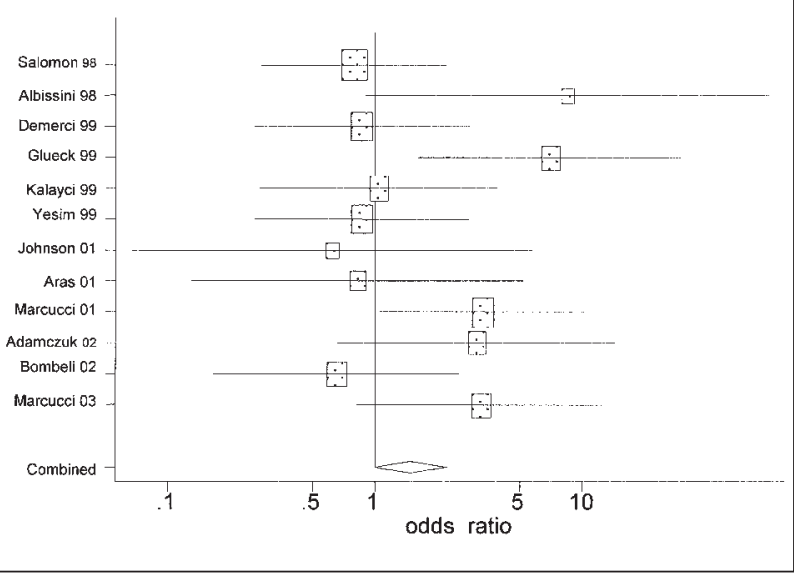

Figure 3: Overall odds ratios and $\mathbf{9 5 \%}$ confidence intervals for RVO with factor $V$ Leiden mutation. The combined odds ratio for the sub-totals for each study design and their $95 \% \mathrm{Cl}$ are indicated by the diamond. The size of the diamond is inversely proportional to the variance of the log odds ratio and the width of the diamond represents the $95 \% \mathrm{Cl}$.

\section{Prothrombin gene (G20I0A) mutation}

In total, 12 case-control studies on the role of prothrombin gene mutation in RVO were found $(19,23,29,31,32,34,36,37,40$, 41,43 ) with a total of 700 patients with any type of retinal vein occlusion and 1334 control subjects. The odds ratio's were between 0.6 and 3.5. The overall odds ratio for prothrombin gene mutation for the risk of RVO was 1,6 (95\% confidence interval 0.8 to 3.2$)$, with no heterogeneity $(\mathrm{p}=0.7)$. Five studies in which none of the patients had the mutation and one study in which none of the controls had the mutation could not be included in the calculation.

\section{Deficiencies of physiological inhibitors of coagulation}

Deficiencies of natural anticoagulation (antithrombin, protein $\mathrm{S}$ and protein $\mathrm{C}$ ) were not commonly reported in RVO. Table 1 shows the results of the case-control studies that were performed on this subject $(22,23,31,37,42,44)$.

\section{Protein $\mathbf{C}$, protein $\mathbf{S}$ and antithrombin}

In total, 6 case-control studies on the role of protein $\mathrm{C}$ were analysed. A total of 351 patients with any type of retinal vein occlu-

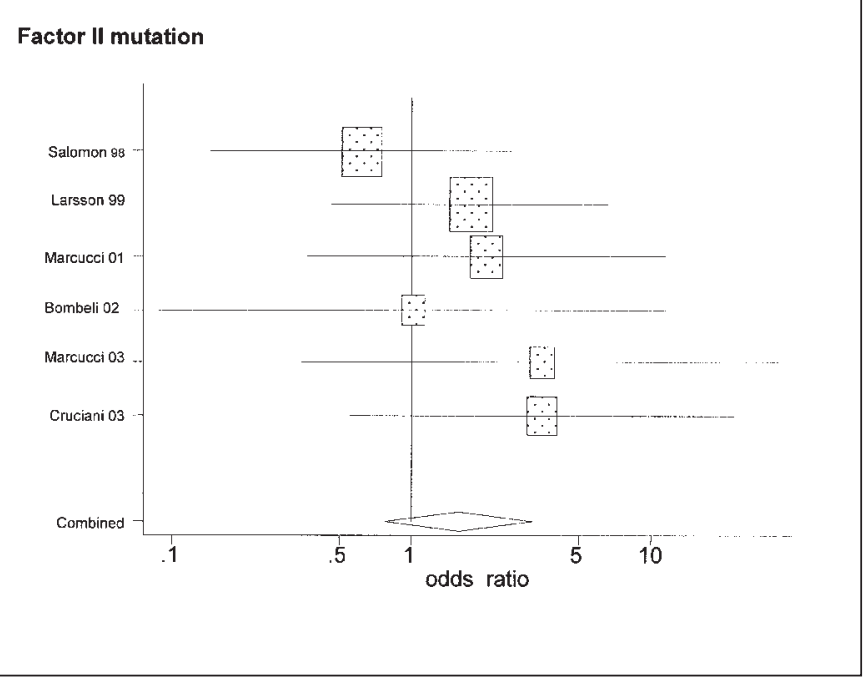

Figure 4: Overall odds ratios and $\mathbf{9 5 \%}$ confidence intervals for RVO with prothrombin gene mutation. The combined odds ratio for the sub-totals for each study design and their $95 \% \mathrm{Cl}$ are indicated by the diamond. The size of the diamond is inversely proportional to the variance of the log odds ratio and the width of the diamond represents the $95 \% \mathrm{Cl}$.

sion were compared with 342 control subjects. Eleven patients had protein $\mathrm{C}$ deficiency compared to 0 controls.

In total, 6 case-control studies on the role of protein $\mathrm{S}$ were analysed. A total of 351 patients with any type of retinal vein occlusion were compared with 349 control subjects. Four patients had protein $\mathrm{S}$ deficiency compared to 0 controls.

In total, 5 case-control studies on the role of antithrombin were analysed. A total of 324 patients with any type of retinal vein occlusion were compared with 281 control subjects. Two patients had antithrombin deficiency compared to 1 control.

\section{Anticardiolipin antibodies and lupus anticoagulant}

In total, 7 case-control studies on the role of anticardiolipin antibodies (ACA) in RVO were found $(19,22,23,45-47)$ with a total of 412 patients with any type of retinal vein occlusion and 508 control subjects. The odds ratio's were between 2.1 and 8.5 (Fig. $5)$. The overall odds ratio for anticardiolipin for the risk of RVO was $3.9(95 \%$ CI 2.3 to 6.7$)$ with no heterogeneity ( $p=0.69)$. In all studies both IgM and IgG antibodies were determined, but in the analysis the results were combined. Overall, IgG antibodies were more prevalent.

Table I: Deficiencies of natural anticoagulants (antithrombin, protein S and protein C) in patients with RVO.

\begin{tabular}{|c|c|c|c|c|c|c|c|c|c|c|c|c|}
\hline \multirow[b]{2}{*}{ Reference } & \multicolumn{4}{|c|}{ Protein C } & \multicolumn{4}{|c|}{ Protein S } & \multicolumn{4}{|c|}{ Antithrombin } \\
\hline & $\begin{array}{l}\text { patients } \\
\text { positive }\end{array}$ & $\begin{array}{l}\text { patients } \\
\text { negative }\end{array}$ & $\begin{array}{l}\text { controls } \\
\text { positive }\end{array}$ & $\begin{array}{l}\text { controls } \\
\text { negative }\end{array}$ & $\begin{array}{l}\text { patients } \\
\text { positive }\end{array}$ & $\begin{array}{l}\text { patients } \\
\text { negative }\end{array}$ & $\begin{array}{l}\text { controls } \\
\text { positive }\end{array}$ & $\begin{array}{l}\text { controls } \\
\text { negative }\end{array}$ & $\begin{array}{l}\text { patients } \\
\text { positive }\end{array}$ & $\begin{array}{l}\text { patients } \\
\text { negative }\end{array}$ & $\begin{array}{l}\text { controls } \\
\text { positive }\end{array}$ & $\begin{array}{l}\text { controls } \\
\text { negative }\end{array}$ \\
\hline Tekeli (44) & 9 & 36 & 0 & 20 & 2 & 43 & 0 & 20 & I & 45 & 0 & 20 \\
\hline Marcucci (23) & 0 & 100 & 0 & 100 & 0 & 100 & 0 & 100 & 0 & 100 & 0 & 100 \\
\hline Kadayifcilar (42) & 2 & 52 & 0 & 19 & 1 & 53 & 0 & 19 & I & 54 & 1 & 19 \\
\hline Bombeli (37) & 0 & 68 & 0 & 120 & 0 & 68 & 0 & 120 & 0 & 68 & 0 & 120 \\
\hline Lahey (22) & 0 & 55 & 0 & 21 & 1 & 54 & 0 & 21 & 0 & 55 & 0 & 21 \\
\hline Cruciani (3I) & 0 & 29 & 0 & 62 & 0 & 29 & 0 & 69 & & & & \\
\hline
\end{tabular}




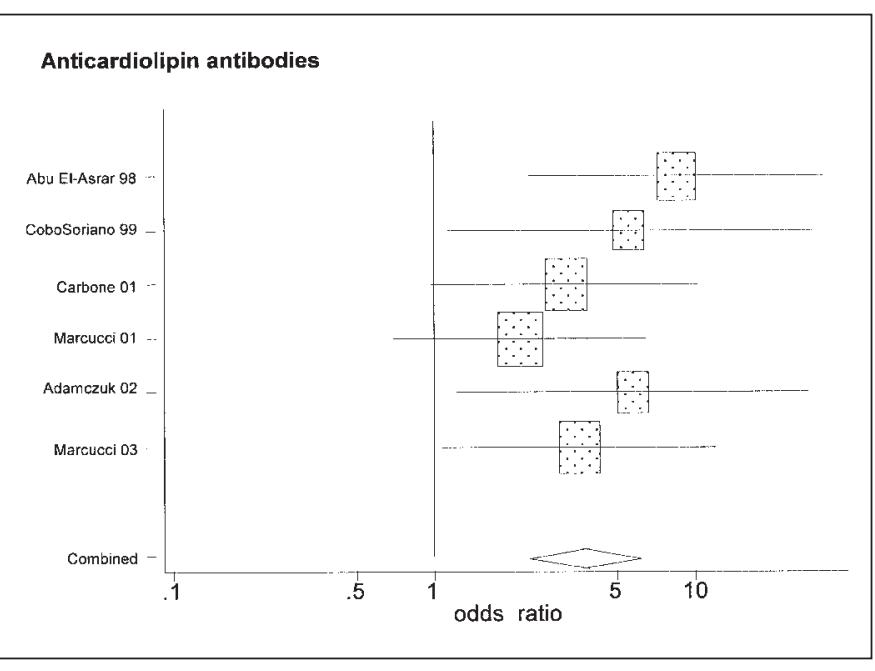

Figure 5: Overall odds ratios and $95 \%$ confidence intervals for RVO with anticardiolipin antibodies. The combined odds ratio for the sub-totals for each study design and their $95 \% \mathrm{Cl}$ are indicated by the diamond. The size of the diamond is inversely proportional to the variance of the log odds ratio and the width of the diamond represents the $95 \% \mathrm{Cl}$

In total, 5 case-control studies on the role of lupus anticoagulant (LAC) were analysed $(19,22,23,45,46)$. A total of 315 patients with any type of retinal vein occlusion were compared with 382 control subjects. Sixteen patients had lupus anticoagulant compared to 3 controls (Table 2).

\section{Discussion}

RVO is a major cause of ocular morbidity. The precise mechanisms leading to thrombosis in RVO has not yet been clearly elucidated. Several risk factors have been identified, including hypertension, diabetes, history of cardiovascular disease, hypercholesterolemia, increased ocular pressure and glaucoma $(4-6,8,9,11$, 13). The role of rheologic or coagulation factors in the development of RVO remains unclear.

Thrombophilic risk factors, such as antithrombin deficiency, protein $\mathrm{C}$ and $\mathrm{S}$ deficiency, hyperhomocysteinemia, factor $\mathrm{V}$ and II mutation and antiphospholipid antibodies have been associated with venous thromboembolism (VTE). Over the past few years an increasing number of studies have evaluated the possible role of these thrombophilic factors in the pathogenesis of RVO. The problem is that many of the available studies have assessed only one or a few factors, often in a limited number of patients. The major problem encountered with these kind of

Table 2: Lupus anticoagulant in patients with RVO.

\begin{tabular}{|l|l|l|l|l}
\hline & $\begin{array}{l}\text { patients } \\
\text { positive }\end{array}$ & $\begin{array}{l}\text { patients } \\
\text { negative }\end{array}$ & $\begin{array}{l}\text { controls } \\
\text { positive }\end{array}$ & $\begin{array}{l}\text { controls } \\
\text { negative }\end{array}$ \\
\hline Marcucci (23) & 2 & 98 & 0 & 100 \\
\hline Lahey (22) & 3 & 52 & 0 & 28 \\
\hline Adamczuk (19) & 3 & 34 & 3 & 141 \\
\hline Marcucci (28) & 5 & 50 & 0 & 61 \\
\hline Carbone (46) & 3 & 65 & 0 & 49 \\
\hline
\end{tabular}

studies is the number of patients required to define an association.

This meta-analysis has thoroughly evaluated the most important thrombophilic risk factors in RVO. It is demonstrated that hyperhomocysteinemia and anticardiolipin antibodies are associated with RVO. The effects on factor V Leiden and factor II mutation are less than observed in VTE. An association between protein $\mathrm{C}, \mathrm{S}$ antithrombin and RVO was not demonstrated.

Regarding homocysteine genetic and environmental factors have been reported to influence plasma levels. In particular, among the genetic factors, a polymorphism (C667T) in the 5-10 methylenetetrahydrofolate reductase (MTHFR) gene has been reported to affect homocysteine levels.

An elevated level of homocysteine is generally accepted to be a risk factor for systemic vascular disease and venous thrombosis. Odds ratio's of 2-3 have been reported (49-51). It appears to have a deleterious effect on arterial vascular endothelium and may induce platelet aggregation, lipid accumulation and thrombosis. The large meta-analysis of Wald et al. showed a significant association between serum homocysteine concentration and ischemic heart disease and deep vein thrombosis (49). In the MTHFR studies, the difference in homocysteine concentration arisen from a single gene mutation are allocated at random. The fact that the MTHFR 677 TT genotype is a risk factor for both venous thrombosis and arterial vascular disease, strongly suggests that the association between homocysteine and these diseases is causal $(49,50)$. In our meta-analysis the odds ratio for homocysteine $>95^{\text {th }}$ percentile was $8.9(95 \%$ CI 5.7 to 13.7$)$. This is higher than reported for venous thrombosis (51). This is probably due to the selection of patients in the studies, small studies and insufficient correction for age. Although the confidence intervals for the effect of MTHFR were wide, the point estimate is similar to what was found for VTE and arterial vascular disease $(17,49,51)$

There have been conflicting reports on the prevalence of FV Leiden mutation in patients with RVO, with some authors reporting a high similar rate to those known from venous thrombosis of other locations $(43,52)$, but others found much lower rates $(53,54)$.

FV Leiden and FII mutation are undoubtedly a risk factor for thrombosis of large veins with reported odds ratio's of 5-6, but as demonstrated in figures 3 and 4, odds ratio's are lower for retinal vein occlusion. At present the associated risk is insufficient on its own to recommend testing of all patients with retinal vascular occlusion for FV Leiden and FII mutation. The same applies for antithrombin and protein $\mathrm{C}$ and $\mathrm{S}$ deficiency.

Another mechanism for hypercoagulability appears to be the activity of circulating immune complexes against membrane phospholipids and plasma proteins (i.e. LAC and ACA). A clear association between ACA was demonstrated in figure 4 . These circulating immune complexes may lead to thrombo-embolic arterial and venous occlusions. The detection of these antiphospholipid antibodies is also important because of the possible systemic complications of the syndrome: recurrent spontaneous abortions, deep venous thrombosis and arterial thrombosis. The first manifestation of antiphospholipid antibodies may be RVO.

Several studies indicate that antiphospholipid antibodies may play a role in the development of atherosclerosis. Induction of a prothrombotic vascular endothelial microenvironment could 
be involved in the pathogenesis of $\operatorname{RVO}(55,56)$. Carbone et al. (46) found that patients with antiphospholipids and RVO exhibited a high frequency of ANA, low C4 levels, low CH100 activity, elevated IgA and increased circulating immune complexes. It was suggested that these patients could define a subset prone to evolve to another systemic automimmune disease such as systemic lupus erythematosus (SLE). Some immunological features, like positive ANA and increased circulating immune complexes, in patients with antiphospholipid antibodies and RVO might distinguish those individuals from immunologic ocular diseases. These patients should be monitored for the development of connective tissue diseases (46).

The retrospective design of most of the included studies is a limitation of this meta-analysis and the disadvantages of retrospective studies in determining blood parameters after an occlusive event have been highlighted earlier. Disadvantages of metaanalyses include inappropriate pooling of data, acknowledged and covert duplication of data, and publication bias. Publication bias when studies with contrary or inconclusive results are not published is a potentially serious limitation of a meta-analysis. However, synthesis of data from multiple studies can overcome limitations of small sample sizes when conclusions are drawn from single studies.

Based on this analysis it seems that the risk profile for arterial disease of the patient with RVO is more important than throm- bophilic risk factors. An explanation for this might be the anatomy of the retinal arteries and veins. RVO is defined as a focal occlusion of a retinal vein at an arteriovenous crossing site. In almost all cases the RVO occurs at crossing sites where the artery is passing anteriorly (superficially) to the vein. The resultant thickening of the artery appears to cause compression of adjacent veins, a process that may be aggravated because the two vessels are confined within a common adventitial sheath. With increased compression, venous blood flow velocity at the crossing site gradually increases until local shear stress causes endothelial cell loss, thrombus formation and vein occlusion.

Regarding thrombophilic risk factors and RVO there is only evidence for an association with hyperhomocysteinemia and anticardiolipin antibodies, factors that are known as risk factors for venous thrombosis as well as for arterial vascular disease. The minor effect of FV Leiden mutation and the protrombin gene mutation (risk factors for venous thrombosis only) suggest that atherosclerosis might be an important factor in the development of CRVO.

In investigating a new patient with RVO one should test for hypertension, lipid abnormalities and diabetes mellitus since retinal venous obstruction may be the presentation of significant cardiovascular morbidity. An extensive and expensive workup for thrombophilic disease is unwarranted in the vast majority of patients with CRVO.

\section{References}

1. David R, Zangwill L, Badarna M et al. Epidemiology of retinal vein occlusion and its association with glaucoma and increased intraocular pressure. Ophthalmologica 1988; 197: 69-74.

2. Beaumont PE, Kang HK. Clinical characteristics of retinal venous occlusions occurring at different sites. Br J Ophthalmol 2002; 86: 572-80.

3. Williamson TH. Central retinal vein occlusion: what's the story? Br J Ophthalmol 1997; 81: 698-704.

4. Dryden RM. Central retinal vein occlusions and chronic simple glaucoma. Arch Ophthalmol 1965; 73 : 659-63.

5. Vannas S, Tarkkanen A. Retinal vein occlusion and glaucoma: tonographic study of the incidence of glaucoma and of its prognosic significance. Br J Ophtalmol 1960; 44: 583-89.

6. Hayreh SS, Zimmerman B, McCarthy MJ et al. Systemic diseases associated with various types of retinal vein occlusion. Am J Ophthalmol 2001; 131: 61-77.

7. Johnston RL, Brucker AJ, Steinmann W et al. Risk factors of branch retinal vein occlusion. Arch Ophthalmol 1985; 103: 1831-32.

8. Prisco D, Marcucci R, Bertini L et al. Cardiovascular and thrombophilic risk factors for central retinal vein occlusion. Eur J Intern Med 2002; 13: 163-9.

9. Prisco D, Marcucci R. Retinal vein thrombosis: risk factors, pathogenesis and therapeutic approach. Pathophysiol Haemost Thromb 2002; 32: 308-11.

10. Rath EZ, Frank RN, Shin DH et al. Risk factors for retinal vein occlusions. A case-control study. Ophthalmology 1992; 99: 509-14.

11. Recchia FM, Brown GC. Systemic disorders associated with retinal vascular occlusion. Curr Opin Ophthalmol 2000; 11: 462-67.

12. Robinson MK, Halpern JI. Retinal vein occlusion. Am Fam Physician 1992; 45: 2661-6.

13. Sperduto RD, Hiller R, Chew E et al. Risk factors for hemiretinal vein occlusion: comparison with risk factors for central and branch retinal vein occlusion: the eye disease case-control study. Ophthalmology 1998; 105: 765-71.

14. Swart J, Reichert-Thoen JW, Suttorp-Schulten MS et al. Diabetes mellitus: a risk factor affecting visual outcome in branch retinal vein occlusion. Eur J Ophthalmol 2003; 13: 648-52.

15. Wenzler EM, Rademakers AJ, Boers GH et al. Hyperhomocysteinemia in retinal artery and retinal vein occlusion. Am J Ophthalmol 1993; 115: 162-7.

16. Sterne JAC, Bradburn MJ, Egger M. Meta-analysis in Stata. Systematic reviews 2001: 347-69.

17. Woolf B. On estimating the relation between blood group and disease. Ann Hum Genet 1955; 19 : 251-3.

18. Abu El-Asrar AM, Abdel Gader AG, Al Amro SA et al. Hyperhomocysteinemia and retinal vascular occlusive disease. Eur J Ophthalmol 2002; 12: 495-500.

19. Adamczuk YP, Iglesias Varela ML, Martinuzzo ME et al. Central retinal vein occlusion and thrombophilia risk factors. Blood Coagul Fibrinolysis 2002; 13 : 623-6.

20. Brown BA, Marx JL, Ward TP et al. Homocysteine: a risk factor for retinal venous occlusive disease. Ophthalmology 2002; 109: 287-90.

21. Cahill M, Karabatzaki M, Meleady R et al. Raised plasma homocysteine as a risk factor for retinal vascular occlusive disease. Br J Ophthalmol 2000; 84: 154-7.

22. Lahey JM, Tunc M, Kearney J et al. Laboratory evaluation of hypercoagulable states in patients with central retinal vein occlusion who are less than 56 years of age. Ophthalmology 2002; 109: 126-31.

23. Marcucci R, Bertini L, Giusti B et al. Thrombophilic risk factors in patients with central retinal vein occlusion. Thromb Haemost 2001; 86: 772-6.

24. Pianka P, Almog Y, Man O et al. Hyperhomocystinemia in patients with nonarteritic anterior ischemic optic neuropathy, central retinal artery occlusion, and central retinal vein occlusion. Ophthalmology 2000; 107: $1588-92$

25. Vine AK. Hyperhomocysteinemia: a risk factor for central retinal vein occlusion. Am J Ophthalmol 2000; 129: 640-4

26. Weger M, Stanger O, Deutschmann H et al. Hyperhomocysteinemia, but not methylenetetrahydrofolate

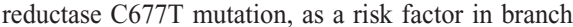
retinal vein occlusion. Ophthalmology 2002; 109: 1105-9.

27. Yildirim C, Yaylali V, Tatlipinar S et al. Hyperhomocysteinemia: a risk factor for retinal vein occlusion. Ophthalmologica 2004; 218: 102-6.

28. Marcucci R, Giusti B, Betti I et al. Genetic determinants of fasting and post-methionine hyperhomocysteinemia in patients with retinal vein occlusion. Thromb Res 2003; 110: 7-12.

29. Boyd S, Owens D, Gin T et al. Plasma homocysteine, methylene tetrahydrofolate reductase C677T and factor II G20210A polymorphisms, factor VIII, and VWF in central retinal vein occlusion. Br J Ophthalmol 2001; 85: 1313-15.

30. Cahill M, Karabatzaki M, Donoghue $C$ et al. Thermolabile MTHFR genotype and retinal vascular occlusive disease. Br J Ophthalmol 2001; 85: 88-90.

31. Cruciani F, Moramarco A, Curto T et al. MTHFR C677T mutation, factor II G20210A mutation and factor V Leiden as risks factor for youth retinal vein occlusion. Clin Ther 2003; 154: 299-303.

32. Glueck CJ, Bell H, Vadlamani L et al. Heritable thrombophilia and hypofibrinolysis. Possible causes of retinal vein occlusion. Arch Ophthalmol 1999; 117: 43-9.

33. Larsson J, Hultberg B, Hillarp A. Hyperhomocysteinemia and the MTHFR C677T mutation in central retinal vein occlusion. Acta Ophthalmol Scand 2000; 78: 340-3.

34. Salomon O, Moisseiev J, Rosenberg N et al. Analysis of genetic polymorphisms related to thrombosis and 
other risk factors in patients with retinal vein occlusion. Blood Coagul Fibrinolysis 1998; 9: 617-22.

35. Weger M, Stanger O, Deutschmann H et al. Hyperhomocysteinemia and MTHFR C677T genotypes in patients with central retinal vein occlusion. Graefes Arch Clin Exp Ophthalmol 2002; 240: 286-90.

36. Aras S, Yilmaz G, Alpas I et al. Retinal vein occlusion and factor V Leiden and prothrombin $20210 \mathrm{G}$ :A mutations. Eur J Ophthalmol 2001; 11: 351-5.

37. Bombeli T, Basic A, Fehr J. Prevalence of hereditary thrombophilia in patients with thrombosis in different venous systems. Am J Hematol 2002; 70: 126-32.

38. Demirci FY, Kucukkaya R, Akarcay K et al. Ocular involvement in primary antiphospholipid syndrome. Int Ophthalmol 1998; 22: 323-9.

39. Johnson TM, El Defrawy S, Hodge WG et al. Prevalence of factor $\mathrm{V}$ Leiden and activated protein $\mathrm{C}$ resistance in central retinal vein occlusion. Retina 2001;21: 161-6.

40. Kalayci D, Gurgey A, Guven D et al. Factor V Leiden and prothrombin 20210 A mutations in patients with central and branch retinal vein occlusion. Acta Ophthalmol Scand 1999; 77: 622-24.

41. Marcucci R, Bertini L, Liotta AA et al. Activated protein $\mathrm{C}$ resistance is a risk factor for central retinal vein occlusion. Ann Ital Med Int 2000; 15: 195-8.
42. Kadayifcilar S, Ozatli D, Ozcebe O et al. Is activated factor VII associated with retinal vein occlusion? Br J Ophthalmol 2001; 85: 1174-8.

43. Larsson J, Hillarp A, Olafsdottir E et al. Activated protein $\mathrm{C}$ resistance and anticoagulant proteins in young adults with central retinal vein occlusion. Acta Ophthalmol Scand 1999; 77: 634-7.

44. Tekeli O, Gursel E, Buyurgan H. Protein C, protein $\mathrm{S}$ and antithrombin III deficiencies in retinal vein occlusion. Acta Ophthalmol Scand 1999; 77: 628-30.

45. Abu El-Asrar AM, Abdel Gader AG, Al Amro S et al. Hypercoagulable states in patients with retinal venous occlusion. Doc Ophthalmol 1998; 95: 133-43.

46. Carbone J, Sanchez-Ramon S, Cobo-Soriano R et al. Antiphospholipid antibodies: a risk factor for occlusive retinal vascular disorders. Comparison with ocular inflammatory diseases. J Rheumatol 2001; 28 : 2437-41.

47. Cobo-Soriano R, Sanchez-Ramon S, Aparicio MJ et al. Antiphospholipid antibodies and retinal thrombosis in patients without risk factors: a prospective case-control study. Am J Ophthalmol 1999; 128: $725-32$.

48. den Heijer M, Lewington S, Clarke R. Homocysteine, MTHFR and risk of venous thrombosis: a metaanalysis of published epidemiological studies. J Thromb Haemost 2005; 3: 292-9.
49. Wald DS, Law M, Morris JK. Homocysteine and cardiovascular disease: evidence on causality from a meta-analysis. BMJ 2002; 325: 1202.

50. den Heijer M. Hyperhomocysteinaemia as a risk factor for venous thrombosis: an update of the current evidence. Clin Chem Lab Med 2003; 41: 1404-7. 51. den Heijer M, Rosendaal FR, Blom HJ et al. Hyperhomocysteinemia and venous thrombosis: a metaanalysis. Thromb Haemost 1998; 80: 874-77.

52. Greiner K, Hafner G, Dick B et al. Retinal vascular occlusion and deficiencies in the protein $\mathrm{C}$ pathway. Am J Ophthalmol 1999; 128: 69-74.

53. Hodgkins PR, Perry DJ, Sawcer SJ et al. Factor V and antithrombin gene mutations in patients with idiopathic central retinal vein occlusion. Eye 1995; 9 $760-2$.

54. Linna T, Ylikorkala A, Kontula K et al. Prevalence of factor $\mathrm{V}$ Leiden in young adults with retinal vein occlusion. Thromb Haemost 1997; 77: 214-6.

55. Harats D, George J, Levy Y et al. Atheroma: links with antiphopholipid antibodies, Hughes syndrome and lupus. Q J Med 1999;92:57-9.

56. Vaarala O. Antiphospholipid antibodies and atherosclerosis. Lupus 1996; 5: 442-7. 